\title{
El DAÑO MORAL EN EL ARTÍCULO 489 DEL CÓDIGO DEL TRABAJO
}

[The moral damage in the article 489 of the labour code]

\section{Sergio Gamonal C.*}

\section{RESUMEN}

No está clara la naturaleza de la indemnización especial del art. 489 del Código del Trabajo. Algunos autores estiman que es por daño moral y otros que sería de naturaleza punitiva. En este artículo se razona en base a la práctica argumentativa del derecho del trabajo, para demostrar que esta indemnización especial, de 6 a 11 meses de remuneración, es por daño moral.

\section{Palabras clave}

Daño moral - Daños punitivos Indemnización tarifada - Reparación integral del daño.

\section{ABSTRACT}

The nature of additional compensation under art. 489 of the Chilean labour code are unclear. Some authors consider them to be moral damages and others punitive damages. This article reasons on the basis of the argumentative practice of labour law, to show that this additional compensation, 6 to 11 months remuneration, is for moral damages.

\section{KEYWORDS}

Moral damage - Punitive damage Compensation rated by seniority - Full compensation for damage.

Recibido el 12 de julio y aprobado el 30 de octubre de 2016

* Licenciado en Ciencias Jurídicas y Sociales, Universidad de Chile. Profesor de Derecho del Trabajo, Universidad Adolfo Ibáñez, Chile (sergio.gamonal@uai. cl). Dirección postal: Quillay 2546 dpto. 602, Providencia, CP 7510227, Santiago. 


\section{LA INDEMNIZACIÓN ESPECIAL DEL ART. 489 DEL CÓDIGO DEL TRABAJO: UNA NATURALEZA POR DESENTRAÑAR}

El procedimiento de tutela de derechos fundamentales ha significado un avance real en los derechos de los trabajadores de nuestro país (arts. 485 a 495 CTCh).

Por tratarse de la vulneración de derechos fundamentales, resulta obvio que el resarcimiento de perjuicios comprenda los daños morales sufridos. Como señala Barros, el grupo de bienes más inequívocamente cautelado por la acción de responsabilidad civil se expresa en los derechos constitucionales $^{1} \mathrm{y}$ los derechos de la personalidad han tenido importancia en la expansión de los intereses morales cautelados ${ }^{2}$.

En el caso del derecho del trabajo chileno, desde los años noventa del siglo pasado, tanto en la jurisprudencia laboral como civil, así como en la doctrina, se ha sostenido la procedencia de la indemnización del daño moral del trabajador, por ejemplo, en materia de acoso sexual o de mobbing, entre otros supuestos ${ }^{3}$. Esta apertura al daño moral comprende desde la etapa precontractual hasta la postcontractual ${ }^{4}$, incluyendo especialmente el término de contrato de trabajo 5 . En los casos de acoso sexual y moral (mobbing), pueden indemnizarse los daños morales tanto en la ejecución como al término del contrato ${ }^{6}$.

${ }^{1}$ Barros, Enrique, Tratado de Responsabilidad Extracontractual (Santiago, Editorial Jurídica de Chile, 2007), p. 228.

2 Barros, Enrique, cit. (1), p. 329.

3 Gamonal C., Sergio, El Daño Moral en el Contrato de Trabajo (2a edición, Santiago, LexisNexis, 2007), pp. 21 ss.

4 Cfr. Süsseskind, Arnaldo, Maranhäo, Délio, Vianna, Segadas, y Texeira, Lima, Instituçiôes de Direito do Trabalho, Tomo I (Sao Paulo, LTr, 1997), I, pp. 631 ss.; Pizarro, Ramón Daniel, Daño moral (Buenos Aires, Hammurabi, 1996), pp. 606 y 607; CaAmaño, Eduardo, El Derecho a la No Discriminación en el Empleo (Santiago, LexisNexis, 2005); Gamonal C., Sergio, Ciudadanía en la Empresa o los derechos fundamentales inespecificos (Montevideo, Fundación de Cultura Universitaria, 2004); Gamonal C., Sergio, El procedimiento de tutela de derechos laborales (2a edición, Santiago, LexisNexis, 2008); Melis, Christian, Los Derechos Fundamentales de los Trabajadores como Limites a los Poderes Empresariales (Santiago, LegalPublishing, 2009); UgarTe, José Luis, El Nuevo Derecho del Trabajo (Santiago, Editorial Universitaria, 2004); Ugarte, José Luis, Tutela de Derechos Fundamentales del Trabajador (Santiago, LegalPublishing, 2009), y VÁzQUeZ Vialard, Antonio, La responsabilidad en el derecho del trabajo (Buenos Aires, Astrea, 1988), p. 766.

${ }^{5}$ Cfr. Gamonal C., Sergio, Evolución del Daño Moral por Término del Contrato de Trabajo en el Derecho Chileno, en Revista de Derecho, Pontificia Universidad Católica de Valparaíso XXXIX (2012) 2ºmestre, pp. 161-176.

${ }^{6}$ Cfr. Gamonal C., Sergio y Prado López, Pamela, El Mobbing o Acoso Moral 
En el procedimiento de tutela, el art. $495 \mathrm{~N}^{\circ} 3$ expresamente señala que la sentencia definitiva debe indicar las medidas de reparación incluyendo "las indemnizaciones que procedan". Estas indemnizaciones comprenden el daño moral, por tratarse de un procedimiento que busca tutelar los derechos fundamentales del trabajador, daño que perfectamente puede ser reparado, en virtud de este procedimiento, mientras el contrato está en ejecución ${ }^{7}$.

Pero la tutela también es aplicable en el término del contrato, en los casos de despido atentatorio de derechos fundamentales y discriminatorio grave, donde también se indemniza el daño moral ${ }^{8}$. En estas situaciones el art. 489 CTCh estatuye que el juez ordenará el pago de una indemnización equivalente a un mes de remuneración por falta de preaviso; más el pago de la indemnización del art. $163 \mathrm{CTCh}$, de años de servicios, si procediere; más el pago de los recargos del art. 168 CTCh y, finalmente, deberá fijar una indemnización adicional no inferior a seis meses ni superior a once meses de la última remuneración mensual.

Hemos sostenido en un artículo anterior que esta indemnización especial de seis a once meses es por el daño material y moral causado al afectado, en especial por este último al afectarse los intereses extrapatrimoniales del trabajador'.

Sin embargo, no se encuentra clara la naturaleza de esta indemnización. Aunque no hay duda de la procedencia del daño moral, algunos autores señalan que se trata de una indemnización sancionatoria y que, en consecuencia, quedaría pendiente la indemnización del daño moral producido ${ }^{10}$.

$\mathrm{Al}$ respecto, Ugarte expresa: "En el caso particular del despido lesivo de derechos fundamentales, de seguro el que generará mayor número de demandas por tutela, la reparación económica se encuentra expresamente prevista y tasada en el haz de indemnizaciones que ya explicamos, pero que no cumbre, a nuestro juicio, el plus de daño moral eventualmente causado por el despido"11.

Para otros, esta indemnización no es una simple tarificación por antigüedad, sino que permite al juez evaluar el daño moral provocado ${ }^{12}$. Sobre este punto señalábamos hace algunos años que: "Por el contrario, opinamos que esta indemnización no es una simple tarificación por antigüedad, sino

Laboral (Santiago, LexisNexis, 2006), pp. 114 y ss., y GAMONAL (2007) pp. 81 a 83, 107 y 151 y ss.

\footnotetext{
7 Gamonal, Sergio, El Daño, cit. (3), pp. 57, 58, 60, 64, 66, 83 y 88.

${ }^{8}$ Gamonal, Sergio, Evolución, cit. (5), pp. 170 y ss.

${ }^{9}$ Gamonal, Sergio Evolución, cit. (5), p. 171.

${ }^{10}$ Ugarte, José Luis, Tutela, cit. (4), p. 90.

${ }^{11}$ Ugarte, José Luis, Tutela, cit. (4), p. 90.

12 Gamonal, Sergio, El procedimiento, cit. (4), p. 39.
} 
que deja un margen de apreciación importante al juez de la causa, acerca del daño producido, especialmente el moral. Es una tarifa abierta con un mínimo y tope. De esta forma, el legislador fija un piso y un tope dentro del cual evaluar los daños, recogiendo la experiencia de otros países en los que se ha evaluado el daño moral laboral por medio de la tarifa legal por años de servicios" 13 .

En las sentencias de tutela encontramos ambas tesis ${ }^{14}$. Por ejemplo, en Jara Miranda con Redbus Urbano ${ }^{15}$, una trabajadora fue acosada sexualmente por su jefe directo solicitando las indemnizaciones del artículo 489 más una reparación extra por daño moral. El tribunal ordenó el pago de la indemnización especial o adicional de 6 meses de remuneración, señalando que esta tarifa de 6 a 11 meses era por daño moral.

Por otro lado, en Omerovich con ISS Servicios Generales ${ }^{16}$, una trabajadora contratada para labores de aseo es despedida porque es coja. La sentencia estimó que el despido había violado la igualdad de oportunidades en el empleo de la demandante, ordenando el pago de la indemnización especial o adicional de 6 remuneraciones y una indemnización extra de otros 6 meses de remuneración por concepto de daño moral. Aquí se diferencia el pago del daño moral de la indemnización tarifada de 6 a 11 meses.

En el mismo sentido, en Negrete con Belenus S.A. ${ }^{17}$ se condena a una empresa por acoso laboral severo, luego de que la trabajadora demandara por despido atentatorio de derechos fundamentales y por despido indirecto. En su sentencia, el tribunal otorgaba una compensación extra por daño moral, sin perjuicio de los pagos decretados al tenor del artículo 489.

Conociendo el recurso de nulidad de la demandada, la décima sala de la Corte de Apelaciones de Santiago lo rechazó afirmando que nada obsta a adjuntar una indemnización extra de daño moral por sobre la tarifa especial de 6 a 11 meses contemplada en dicha norma.

La Corte declara que la indemnización especial (de 6 a 11 meses) es de naturaleza punitiva, lo cual permite adjuntar otra por el daño moral. Los argumentos para esta conclusión son los siguientes (considerando séptimo):

a) La indemnización especial del art. 489 no excluye una eventual indemnización del daño moral.

b) La naturaleza de la indemnización especial es punitiva, ya que busca sancionar el despido abusivo, cumplir una función disuasiva frente a la

\footnotetext{
13 Gamonal, Sergio, El procedimiento, cit. (4), p. 39.

${ }^{14}$ Gamonal, Sergio, Evolución, cit. (5), pp. 172 y ss.

${ }_{15}$ RIT N $^{\circ}$ T-4-2009 del Segundo Juzgado de Letras del Trabajo de Santiago.

${ }_{16}$ RIT N ${ }^{\circ}$ T-63-2011 del Primer Juzgado de Letras del Trabajo de Santiago.

17 RIT T-559-2012 del Primer Juzgado de Letras del Trabajo de Santiago.
} 
violación de bienes especialmente valiosos, no está sujeta a prueba del daño y su monto mínimo y máximo está predeterminado.

c) El principio de reparación integral del daño permite acumular otra indemnización por el daño moral.

En este artículo intentaremos mostrar una óptica distinta desde la vereda del derecho del trabajo, reafirmando nuestra tesis anterior ${ }^{18}$. Para este cometido, primero analizaremos el origen de las indemnizaciones tarifadas en materia laboral. Luego, estudiaremos brevemente los daños punitivos en el derecho. A continuación, postularemos el carácter especial y de daño moral de la del art. 489 sin por ello dejar de admitir, en el capítulo final de este trabajo, que eventualmente puede acumularse una indemnización extra por daño moral más allá de la del art. 489, en casos calificados.

\section{EL ORIGEN DE LAS INDEMNIZACIONES TARIFADAS EN}

\section{DERECHO DEL TRABAJO}

En la práctica argumentativa del derecho del trabajo es común la existencia de indemnizaciones tarifadas por antigüedad. Su naturaleza no es la de una indemnización de tipo compensatoria o reparatoria del daño efectivamente causado, dado que son fijas y dependen de la antigüedad del trabajador. Por ello, la doctrina ha determinado que estas indemnizaciones aluden a una naturaleza de premio a la fidelidad, de previsión y asistencia social y de promoción de la estabilidad en el empleo ${ }^{19}$. En el mismo sentido se ha pronunciado la Corte Suprema de nuestro país ${ }^{20}$.

${ }^{18}$ Gamonal, Sergio, Evolución, cit. (5), p. 171 y Gamonal, Sergio, El procedimiento, cit. (4), p. 39.

19 Gamonal Contreras, Sergio, El Daño Moral por Término del Contrato de Trabajo (Santiago, Editrem, 2000), pp. 54 y 55.

Una tesis un tanto distinta, en el sentido de que esta indemnización no constituiría una prestación por desempleo, sino un resarcimiento por la pérdida de los derechos de antigüedad del trabajador, en Rojas MiÑo, Irene, La naturaleza Jurídica de la Indemnización por Término de Contrato de Trabajo en el Ordenamiento Laboral Chileno, en Revista de Derecho, Pontificia Universidad Católica de Valparaíso XLI (2013) $2^{\circ}$ semestre, pp. 107-143.

${ }^{20}$ Suazo con Codelco Chile, Corte Suprema, sala civil, recurso de casación Rol No 7270-2009. Vid. Gamonal Contreras, Sergio, El Daño Moral por Término del Contrato de Trabajo, en Revista de Derecho Laboral y Seguridad Social, I Thomson Reuters Chile (2013) 1, pp. 124-128.

Otra sala de la Corte Suprema (la tercera sala o sala constitucional) en la causa López Baleisán Rosa con Municipalidad de Los Andes, Rol N 8871-09, de 23 de octubre de 2012, frente a un caso de acoso laboral donde la trabajadora había ganado demandando por despido indirecto, condenó por responsabilidad extracontractual al pago de una indemnización por daño moral al empleador que era un servicio público 
Para el objetivo de nuestro análisis, resulta de interés pesquisar el origen de este sistema tarifado. Al respecto, aludiremos a tres causas distintas que explican su utilización en derecho laboral, a saber, a) un origen en la autonomía colectiva: inicialmente surgen en las negociaciones colectivas y luego este mecanismo fue recepcionado por las leyes laborales; $b$ ) un origen jurisprudencial: la indemnización tarifada es un derivado de la regla inglesa de término de contrato el siglo XIX; $c$ ) un origen legislativo transaccional: una tarifa laboral permite eximirse de las reglas generales de responsabilidad civil, beneficiando al trabajador y, al mismo tiempo, dando seguridad a la iniciativa empresarial.

No es relevante cuál de todas pueda haber influenciado en nuestro derecho. Lo interesante es que cada una de estas explicaciones nos ayuda a evaluar el alcance de este tipo tarifado de indemnizaciones.

a) Origen en la autonomía colectiva: inicialmente la indemnización tarifada surge en las negociaciones colectivas y luego este mecanismo fue adoptado por las leyes laborales.

En la versión clásica, la indemnización tarifada surge de prácticas adoptadas por el legislador y que fueron originalmente consagradas en las negociaciones colectivas. Como explicaban Camerlynck y Lyon-Caen, en Francia, el contrato individual y en algunos casos la costumbre preveían una indemnización por despido proporcional a la antigüedad, aunque habría sido principalmente la negociación colectiva la que estableció esta modalidad y luego fue adoptada por el legislador ${ }^{21}$.

Para estos autores, se trataba de una indemnización determinada a priori por el perjuicio sufrido a causa de la ruptura contractual, lo que justifica su

municipal (Municipalidad de Los Andes), aplicándole la noción de falta de servicio. En este caso, la trabajadora, producto del acoso, adolecía de un severo deterioro psíquico y físico por lo que le habían diagnosticado un trastorno depresivo recurrente. Esta sentencia menciona expresamente y adhiere a las consideraciones de la sala civil sobre la naturaleza de la indemnización tarifada laboral.

Por su parte, la sala laboral de la Corte Suprema, con fecha 7 de octubre de 2014, fallando la unificación de jurisprudencia Jara con I. Municipalidad de La Ligua, Rol 2746-2014, señaló que las indemnizaciones por término de contrato son de carácter general y buscan resguardar la estabilidad en el empleo, por tanto no inhiben la indemnización de las lesiones extrapatrimoniales como el daño moral (considerando octavo).

${ }^{21}$ Camerlynck, G.H. y Lyon-Caen, G., Derecho del Trabajo (primera edición en francés de 1963, traducción de Juan M. Ramírez, Madrid, Aguilar, 1974), p. 147.

En el mismo sentido: Rivero, Jean y Savatier, Jean, Droit du Travail (décimo tercera edición, París, PUF, 1993), p. 501; Couturier, Gérard, Droit du Travail (tercera edición, París, PUF, 1996), p. 255, y Langé, Daniel, Droit du Travail (París, Ellipses, 2003), p. 86. 
forma de concesión y de cálculo ${ }^{22}$. En el mismo sentido, Piccinini precisa que se buscaba premiar al trabajador despedido en reconocimiento de la duración de la relación laboral casi a título de mera liberalidad, a fin de reparar el daño por el despido y como recompensa por la obra realizada ${ }^{23}$.

En nuestro país también se ha postulado este origen de la indemnización por años de servicio, en los contratos colectivos y actas de avenimiento ${ }^{24}$.

b) Origen jurisprudencial: la indemnización tarifada es un derivado de la regla inglesa de término de contrato el siglo XIX.

La regla inglesa alude a una interpretación protectora del trabajador construida por los tribunales ingleses en el siglo XIX.

No existían normas de término de contrato de trabajo, y sólo quedaba el resabio de las normas de servidumbre (Master and Servant), en donde se presumía que los servicios durarían un año. De esta forma, los tribunales británicos empezaron a dictaminar que, salvo cuando las partes hubieran establecido expresamente un plazo, la contratación de un trabajador se presumiría por un año (yaerly hiring) ${ }^{25}$. Esta regla se basaba en el sistema agrícola de producción, predominante en la era pre industrial. Los tribunales en los primeros tiempos del siglo XIX adaptaron esta regla en favor de los trabajadores, por ejemplo, en Beeston $v$. Collyer, en 1827, donde se acepta la demanda por despido de un trabajador administrativo en base a que no se había estipulado el tiempo por el cual se contrataba.

Si bien se intentó la mantención de esta interpretación durante el siglo XIX, la tesis dominante fue mutando lentamente a la idea de que el contrato indefinido podía terminarse siempre que hubiera preaviso a la contraparte. Por ejemplo, en 1844 se afirma la no inflexibilidad de la regla de la duración anual en Baxter v. Nurse e idéntico criterio se adopta en Fairman v. Oaford, en 1860, en donde se afirma que el preaviso debe ser de 3 meses $^{26}$.

El preaviso como forma de término del contrato tuvo su justificación en el acuerdo expreso de las partes y, en su defecto, en la existencia de una

22 Camerlynck y Lyon-Caen, cit. (21), p. 147.

${ }^{23}$ Piccinini, Iolanda, Equitá e diritto del lavoro (Padua, CEDAM, 1997), pp. 210 y 211.

${ }_{24}$ Walker Errázuriz, Francisco y Arellano Ortiz, Pablo, Derecho de las Relaciones Laborales. Un derecho vivo, (Santiago, Librotecnia, 2014), p. 420.

${ }^{25}$ Galiana Moreno, Jesús M., El Contrato de Trabajo en el Derecho Inglés (Barcelona, Bosch, 1978), pp. 207 a 209.

${ }^{26}$ Galiana, Jesús M., cit. (25), p. 209. 
costumbre generalizada ${ }^{27}$. Luego los tribunales entendieron el preaviso como una cláusula implícita (implied terms) ${ }^{28}$.

La adopción del preaviso, en vez de la presunción del año, fue aceptada tanto por empleadores como por trabajadores y sindicatos. Para los primeros, dado que les permitía adaptar el número de contratados a las necesidades de su empresa y a los segundos porque esta nueva tesis los exoneraba de ser encarcelados en caso de terminar anticipadamente el contrato $^{29}$, o en caso de cambiar de amo (patrón) no incurrían en falta, reglas que estuvieron en vigencia hasta 1867 en la ley de Master and Servant en Gran Bretaña ${ }^{30}$.

El plazo de preaviso debía ser "razonable". En algunos casos un mes, en otros según la periodicidad del salario, en otros considerando la categoría profesional del trabajador, su antigüedad en la empresa, y el carácter temporal o permanente del empleo ${ }^{31}$.

En Latinoamérica encontramos menciones a este origen histórico de la indemnización por años de servicio, en el sentido de que se trataría también de una derivación de la indemnización del preaviso ${ }^{32}$. Primero se contemplaba un preaviso de término en favor del trabajador más largo que el preaviso por renuncia de éste. Dado que para el trabajador era más difícil encontrar un nuevo trabajo que para el empleador buscar un trabajador reemplazante, el plazo de preaviso se fue extendiendo en favor del primero. Sin embargo, esta situación era complicada, el trabajador despedido permanecía realizando su trabajo dentro de la empresa por un número de semanas o meses, antes de que se concretara dicha medida, y

27 Galiana, Jesús M., cit. (25), p. 209.

${ }^{28}$ Galiana, Jesús M., cit. (25), p. 210.

${ }^{29}$ Galiana, Jesús M., cit. (25), p. 210.

30 Sobre la Master and Servant Act, vid. Blackstone, William y Cooley, Thomas M., Commentaries of the Laws of England, Libro1 vol. 1 (tercera edición revisada -la primera es de 1765- incluyendo los comentarios, referencias y notas de Thomas M. Cooley., Chicago, Callaghan and Company, 1884), pp. 422 y 423 respecto de la esclavitud, y 426 y ss. respecto de las responsabilidades y deberes, y p. 429 respecto del cambio de amo estando el criado en servicios para otro.

${ }^{31}$ Galiana, Jesús M., cit. (25), pp. 210 y 211.

32 Deveali, Mario, Lineamientos de Derecho del Trabajo (Buenos Aires, Tipográfica Editores Argentina, 1948), pp. 237 a 239. Autores más contemporáneos siguen citando esta tesis como la "teoría de Mario Deveali" sobre la naturaleza de la indemnización por años de servicio, por ejemplo: MARTORell, Ernesto E., Indemnización del daño moral por despido (2a edición, Buenos Aires, Hammurabi, 1994), p. 114, y Machado, José Daniel y OJeda, Raúl Horacio, Las Indemnizaciones Debidas como Consecuencia de la Extinción de la Relación de Trabajo, en AcKerman, Mario E. (edit.) y Tosca, Diego M. (coord.), Tratado de Derecho del Trabajo, Tomo IV (Buenos Aires, Rubinzal-Culzoni Editores, 2005), pp. 233-471, p. 422. 
claramente fue más práctico que dejara de asistir y sólo se le abonara una indemnización compensatoria de su salario ${ }^{33}$. Así lentamente este beneficio se fue transformando en la indemnización por años de servicio, tarifada según la antigüedad del trabajador despedido, dado que les costaba menos encontrar una nueva ocupación a los jóvenes con menor antigüedad que a los trabajadores maduros más experimentados con varios años de servicio. Esa habría sido la razón del tarifado por antigüedad ${ }^{34}$.

c) Origen legislativo transaccional: una tarifa laboral permite eximirse de las reglas generales de responsabilidad civil, beneficiando al trabajador $\mathrm{y}$, al mismo tiempo, otorgando seguridad a la iniciativa empresarial.

Un caso reciente de instauración de topes tarifarios laborales ha sido el Estado de Montana, en Estados Unidos de Norteamérica, el cual desde 1987 ha establecido un sistema de despido justificado, con la Montana Wrongful Discharge From Employment Act que exige para despedir la existencia de una causa justa ${ }^{35}$. Cabe recordar que en dicho país rige libertad de despido, más conocida como employtment at will, salvo diversas excepciones legales, contractuales y jurisprudenciales ${ }^{36}$. Una excepción de interés es esta ley de Montana, originada en la interpretación protectora de la Corte Suprema estatal, que impuso en sus sentencias la tesis de la justa causa ${ }^{37}$.

Para los empleadores esto constituía una gran incerteza, porque cada despido podía terminar discutido en los tribunales y sujeto a las reglas generales de responsabilidad civil. Por ejemplo, en el caso Flanigan $v$. Prudential Federal Savings $s^{38}$, en 1986, el trabajador (gerente de un banco) recibió 1,3 millones de dólares en daños punitivos, 100 mil dólares por aflicción emocional y 93 mil por daño material ${ }^{39}$. Frente a esta situación los empleadores solicitaron durante la tramitación de la ley de justa causa que se limitara el monto indemnizatorio ${ }^{40}$. Finalmente se aprobó una reparación a los trabajadores con al menos 3 años de antigüedad, limitando

33 Ruprecht, Alfredo, Contrato de Trabajo, en Enciclopedia Jurídica OMEBA, Tomo IV (Buenos Aires, Driskill, 1979), p. 480.

${ }^{34}$ Ruprecht, Alfredo, cit. (33), p. 480.

${ }^{35}$ Morriss, Andrew P., The Story of the Montana Wrongful Discharge from Employment Act: A Drama in 5 Acts, en Estreicher, Samuel y Lester, Gillian (editores), Employment Law Stories (Nueva York, Thomson West, 2007), pp. 237-276.

36 Gamonal C., Sergio y Rosado Marzán, César, El Principio de Protección del Trabajador en el Derecho Norteamericano (Santiago, Thomson Reuters, 2014), pp. 96 a 101.

${ }^{37}$ Morriss, Andrew P., cit. (35), p. 238.

38720 P.2d 257 (Mont. 1986).

${ }^{39}$ Morriss, Andrew P., cit. (35), p. 249.

${ }^{40}$ Morriss, Andrew P., cit. (35), p. 251. 
los daños a tres años de salarios perdidos y beneficios suplementarios ${ }^{41}$. Si bien se trata de topes más que de tarifas, rescatamos la idea transaccional en su establecimiento.

La idea de topes tarifarios y de seguros sociales como excepción de las reglas generales de responsabilidad, favoreciendo de esta forma al empleador, no es nueva en el derecho laboral norteamericano. Como ha precisado Gordon, un incentivo para que los empleadores aceptaran la legislación social en la época del New Deal, fue que los seguros sociales (worker's compensations) limitaban los costos del empleador en relación a las indemnizaciones decretadas por los tribunales civiles, según las reglas generales de responsabilidad ${ }^{42}$.

Como podemos apreciar, no obstante las diferentes explicaciones en cuanto a sus orígenes, la indemnización por años de servicio y los topes indemnizatorios dentro del derecho del trabajo tienen una lógica protectora y de certeza para ambas partes.

Por un lado, se exime al trabajador de tener que probar perjuicios, lo cual podría ser muy complicado. Por otro, se otorga certeza a ambas partes, en el sentido de que el trabajador sabe qué monto indemnizatorio recibirá por término de contrato y el empleador conoce de antemano el costo del despido.

En materia de accidentes del trabajo opera la misma lógica. Como sugiere Barros, en derecho comparado el establecimiento de un régimen de responsabilidad estricta o de seguro obligatorio con indemnizaciones tasadas por el legislador, conlleva una eliminación del régimen general de responsabilidad civil $^{43}$. Esta exclusividad del régimen indemnizatorio se justifica porque la estandarización favorece un régimen compensatorio simple, ya que no requiere de prueba, ni admite defensas, rebajando de esta forma los costos administrativos ${ }^{44}$.

\section{LOS DAÑOS PUNITIVOS EN EL DERECHO}

Los daños punitivos o punitive damages nacen dentro del common law, $\mathrm{y}$ han tenido un desarrollo bastante llamativo en el derecho norteamericano ${ }^{45}$.

${ }^{41}$ Morriss, Andrew P., cit. (35), p. 252.

42 Gordon, Robert W., Corporate Law Practice as a Public Calling, en Maryland Law Review, 49 (1990) 2, p. 271.

${ }^{43}$ Barros, Enrique, cit. (1), p. 700.

${ }^{44}$ Barros, Enrique, cit. (1), p. 700.

45 Salvador Coderch, Pablo, Punitive Damages, en InDret Revista para el Análisis del Derecho, (2000) 01, pp. 1-17, p. 3.

(visible en internet: www.indret.com) 
Por el contrario, en los sistemas de Civil law los jueces no suelen decretar, en los juicios por responsabilidad, daños punitivos o sancionatorios sino indemnizaciones de tipo reparatorio ${ }^{46}$, aunque la tendencia pareciera ir hacia una cierta aceptación de daños punitivos en casos específicos ${ }^{47}$, por ejemplo en España, Alemania y Francia ${ }^{48}$.

Las indemnizaciones punitivas exceden el perjuicio efectivo producido a la víctima, y son percibidas por el demandante a título de pena privada ${ }^{49}$.

La indemnización por daños punitivos no busca reparar o compensar a la víctima, sino sancionar una conducta particularmente antijurídica (función vindicativa o retributiva) y generar un efecto de disuasión a futuro respecto de otros eventuales infractores (función preventiva). Por su intermedio, se sancionan conductas graves, se previene a otros posibles agresores y se restablece el equilibrio emocional de la víctima ${ }^{50}$.

La indemnización punitiva participa de la sanción penal, en el sentido de que por medio de una pena que no atiende al daño efectivo logra su cometido, a saber, la sanción y disuasión ${ }^{51}$.

Existen diversas críticas a la aceptación de los daños punitivos en la responsabilidad civil. Se señala que constituirían un enriquecimiento injusto por otorgar un monto mayor del daño real sufrido por la víctima ${ }^{52}$. También se ha argumentado que, por ser una sanción, el proceso en que

El primer caso donde la Corte Suprema federal de Estados Unidos de Norteamérica establece la plena procedencia de daño punitivos es Day $v$. Woodworth, en 1851. Cfr. Mallor, Jane P., Punitive Damages for Wrongful Discharge of At Will Employees, en William and Mary Law Review, 26 (1985), p. 472.

46 Salvador, Pablo, cit. (45), p. 3.

47 García Matamoros, Laura Victoria y Herrera Lozano, María Carolina, El concepto de los daños punitivos o punitive damages, en Estudios Socio-Jurídicos, Bogotá 5 (2003) (1), pp. 220 y ss.

${ }^{48}$ Salvador, Pablo, cit. (45), pp. 4 y 5. Este autor precisa, en todo caso, que los ejemplos de estos países se refieren a punitive damages en sentido restringido, dado que son impuestos por el legislador o el tribunal de casación y por un monto determinado.

${ }^{49}$ Barros, Enrique, cit. (1), p. p. 218.

50 García y Herrera, cit. (47), p. 215.

También se ha planteado por algunos autores que los daños punitivos pueden tener incluso un fin compensatorio, y que, en los hechos, los primeros casos involucraban el honor de las personas. En ciertas situaciones la indemnización compensatoria puede ser insuficiente para reparar plenamente el daño y se requiere de una indemnización punitiva, como en los casos de discriminación. Cfr. KLINCK, Robert A., Symposium: Reforming Punitive Damages. The Punitive Damage Debate, en Harvard Journal on Legislation, 38 (2001), pp. 478 y 479.

${ }^{51}$ Barros, Enrique, cit. (1), p. p. 304.

52 García y Herrera, cit. (47), p. 222. 
debieran decretarse tendría que estar sometido a las reglas penales y no civiles, para respetar el debido proceso ${ }^{53}$. Asimismo, se ha sostenido que los daños punitivos facilitan la arbitrariedad judicial (sobre todo en el caso de los jurados ${ }^{54}$ y y crean inseguridad jurídica en los ciudadanos ${ }^{55}$. Además, se discute su real efecto disuasorio ${ }^{56}$ y se ha afirmado que fomentan la litigación especulativa ${ }^{57}$. Por último, se ha hecho presente la tensión que significan para el derecho privado los daños punitivos, dado que su aceptación vulneraría el principio de reparación integral del daño afectando la justicia correctiva ${ }^{58}$.

En el derecho norteamericano la jurisprudencia ha precisado que los daños punitivos deben ser razonables y proporcionales en relación a la reparación del daño real. En State Farm Mutual Insurance Co. v. Campbell la Corte Suprema norteamericana declaró desproporcionada una indemnización punitiva de 145 millones de dólares, en circunstancias de que la indemnización del daño real era sólo de 1 millón de dólares ${ }^{59}$.

Los tribunales norteamericanos han ampliado la aplicabilidad de los daños punitivos a temas tan diversos como las violaciones a los derechos civiles, la venta de productos defectuosos, el incumplimiento contractual de mala fe, las violaciones a las leyes de seguridad del estado, y los incumplimientos de obligaciones extracontractuales ${ }^{60}$.

53 Barros, Enrique, cit. (1), p. 306.

${ }^{54}$ KuINCK, Robert, cit. (50), pp. 473 a 475.

${ }^{\mathrm{Se}}$ ha señalado que en ciertos casos la actitud de los jurados es de tipo "Robin Hood” en la estimación de los daños punitivos. Cfr. Mallor, Jane, cit. (45), p. 476.

55 García y Herrera, cit. (47), p. 223.

${ }^{56}$ PRIEST, George L., La reforma del régimen de daños punitivos: el caso de Alabama, en Rosenkrantz, Carlos F. (comp.), La Responsabilidad Extracontractual (traducción de Carlos F. Rosenkrantz, Barcelona, Gedisa, 2005), pp. 301-311. E incluso peor, Priest precisa que los daños punitivos dañan a los consumidores dado que el costo de los mismos se traspasa al precio del producto. Ibíd. p. 305.

57 Barros, Enrique, cit. (1), 307.

58 Pereira Fredes, Esteban, Un Alegato a Favor de las Consideraciones Punitivas en el Derecho Privado, en Revista de Derecho, Escuela de Posgrado U. de Chile, 7 (2015), pp. 61-78. En el mismo sentido Barros, Enrique, cit. (1), p. 307.

59 Kemp, David S. (2013), The Constitution and Punitive Damages: A Ten years Anniversary Discussion of State Farm v. Campbell, en Verdict, Legal Analysis and Commentary from Justia, (2013).

(visible en internet: https://verdict.justia.com/2013/04/08/the-constitutionand-punitive-damages).

${ }^{60}$ Cooter, Robert D., Punitive Damages, Social Norms, and Economic Analysis, en Law and Contemporary Problems, 60 (1997) 3, p. 75 y Mallor, Jane, cit. (45), p. 450.

En opinión de Priest, el aumento de las condenas a daños punitivos en Estados 
En forma excepcional se ha aceptado la procedencia de daños punitivos laborales en el despido abusivo en Estados Unidos ${ }^{61}$.

En el caso de nuestro país, se ha hecho presente que no es infrecuente que el daño moral sea aplicado por la judicatura con un fin retributivo ${ }^{62}$. Como señala Tapia, aunque la doctrina estima necesario precisar las concepciones de daño moral utilizadas por las sentencias, con el fin de objetivar la valoración del daño y comprender mejor los fundamentos de la decisión, existen incentivos perversos para que todo siga igual. La Corte Suprema deja a los jueces de fondo la facultad de evaluar el daño moral prescindiendo incluso de prueba y cuando las sentencias precisan y fundan el daño reparable se arriesgan a que sus resoluciones sean revocadas, lo que incentiva fallos lacónicos ${ }^{63}$.

En responsabilidad extracontractual, Pereira ha hecho presente que los jueces utilizan consideraciones punitivas para fundar sus sentencias de daño moral, aunque tienden a negar este hecho ${ }^{64}$. Para este autor, los incrementos del quantum indemnizatorio por daño moral, en base a consideraciones retributivas o preventivas, generan una tensión con el principio de reparación integral del daño (no debe indemnizarse un monto mayor al daño efectivamente causado) ${ }^{65}$. En este contexto, encontramos a la par en nuestro derecho civil justificaciones de justicia correctiva y exigencias de justicia retributiva ${ }^{66}$. Como forma de dar consistencia a esta tensión, Pereira recurre al art 1558 del Código Civil, dado que se reconoce en este precepto que el incumplimiento contractual doloso permite amplificar la carga reparatoria de perjuicios, debiendo el infractor responder por los perjuicios directos previstos e imprevistos. Es así como podemos apreciar que subyacen consideraciones retributivas en la sanción del dolo a nivel

Unidos no tiene sustento teórico, y se basaría en la teoría de la responsabilidad empresarial, que postula que debe ser la empresa la responsable por las lesiones causadas por los productos que coloca en el comercio y por las pérdidas que provoque al perseguir su interés comercial. Aunque esta hipótesis no está del todo clara, Priest hace presente que de esta forma se considera que el consumidor no tiene rol alguno en evitar el daño o prevenir el riesgo. Vid. Priest, George L., Punitive Damages and Enterprise Liability, en Southern California Law Review, 56 (1982), pp. 123-132.

${ }^{61}$ Mallor, Jane, cit. (45), p. 479 a 484.

${ }^{62}$ Barros, Enrique, cit. (1), pp. 305 y 308 y ss. y Pereira, Esteban, cit. (58), pp. 62 y 63.

${ }^{63}$ Tapia Rodríguez, Mauricio, Código Civil 1855-2005, Evolución y Perspectivas, (Santiago, Editorial Jurídica de Chile, 2005), p. 303.

${ }^{64}$ Pereira, Esteban, cit. (58), p. 62.

${ }^{65}$ Pereira, Esteban, cit. (58), p. 65.

${ }^{66}$ Pereira, Esteban, cit. (58), p. 66. 
contractual y lo mismo ocurre con la Ley $\mathrm{N}^{\circ} 19.628(28 / 08 / 1999)$ sobre protección de la vida privada ${ }^{67}$.

Por otro lado, el Tribunal Constitucional chileno se ha referido a la constitucionalidad de los daños punitivos en dos sentencias. Primero, en el requerimiento de inconstitucionalidad Rol No 541-2006, relativo a la disposición contemplada en el artículo 42, inciso primero, del DFL $\mathrm{N}^{\circ}$ 164, de 1991, Ley de Concesiones (cuyo texto fue refundido, coordinado y sistematizado por el Decreto 900 de Obras Públicas, del 18/12/1996), en cuanto dispone que el juez de la causa debe, además de ordenar el pago de la suma adeudada por no pago del TAG, imponer el pago de una indemnización compensatoria por un monto de cuarenta veces el valor de aquella suma, más reajustes e intereses, o, en su defecto, a título también de indemnización compensatoria, el pago de dos unidades tributarias mensuales, debiendo siempre imponer el monto que fuere mayor de entre los dos señalados.

Este requerimiento fue rechazado estimándose constitucional el precepto cuestionado. La sentencia fue clara en cuanto a la pertinencia de una indemnización punitiva: "Forzoso es concluir, entonces, que la sanción civil derivada del precepto en examen no constituye la pena de confiscación de bienes $y$, cuando más, incide en el cumplimiento de una obligación establecida por la ley, que deriva de la función social de la propiedad, referida a su utilidad pública" (c. décimo tercero), agregando luego que la denominada indemnización por la ley es esencialmente una pena civil, impuesta como sanción del incumplimiento de una obligación, y que la "verificación del daño es ajena a la figura legal, en este caso, y la resolución del asunto no la comprende" (c. décimo noveno).

Alguno años más tarde, en el requerimiento Rol No 1564-09 de 7 de diciembre de 2010, el Tribunal Constitucional rechaza un requerimiento de inaplicabilidad del art. $4^{\circ}$ de la Ley $N^{\circ} 19.983(15 / 12 / 2004)$, que Regula la transferencia y otorga mérito ejecutivo a la factura, en su texto modificado por la Ley No 20.323 (20/01/2009), que Modifica la Ley 19.983 con el objeto de facilitar la factorización de facturas por pequeños y medianos empresarios.

Se discutía en este requerimiento, entre otras materias, la sanción por la no entrega de recibo de las mercaderías o servicios al momento del recibo de la factura, dado que el artículo cuestionado decreta una indemnización por dicha conducta de dos a cinco veces el monto de la factura, calificada por el requirente como una suma "inmensa".

$\mathrm{Al}$ respecto, el Tribunal Constitucional precisó que las indemnizaciones

${ }^{67}$ Pereira, Esteban, cit. (58), pp. 70 y 71. 
en derecho privado pueden ser establecidas por las partes, el legislador o el juez y que, en este caso, el legislador, por el imperativo de orden público económico (la libre circulación de un crédito que conste en una factura) impone esta indemnización de, a lo menos, dos veces el monto de la misma. Esta indemnización no puede ser aplicada en forma discrecional, sino ateniéndose a los parámetros establecidos por ley (considerandos 30 a 32). La mayoría del tribunal es enfática al señalar que la Constitución no limita al legislador a la hora de establecer indemnizaciones (c. 37), agregando que: "la regulación establecida se enmarca dentro de patrones razonables. En efecto, el legislador optó por fijar el rango dentro del cual el juez debe aplicar la indemnización. En ese rango, está facultado para adjudicar en atención a los antecedentes que emanan de las piezas del proceso, pudiendo aplicar la indemnización en los cuatro montos descritos, según la ponderación que efectúe en torno a la intensidad del daño ocasionado al interés público o privado. Sólo asi se explica que el monto de la indemnización, en la escala fijada por el legislador pueda resultar, en la generalidad de los casos, muy inferior a los resultados de una valoración abierta de los perjuicios producidos por el incumplimiento; situaciones en las cuales la indemnización pudiera eventualmente elevarse de manera superlativa al tener que considerar conjuntamente, el daño emergente, el lucro cesante y el daño moral' (c. 38) ${ }^{68}$.

${ }^{68}$ Se lee en esta sentencia que: "la Constitución no prejuzga acerca de cuál debe ser el fundamento de la obligación de reparar un daño sufrido por una persona. En nuestro derecho la obligación de reparar un daño no es siempre atribuible al dolo o culpa del responsable del mismo, sino que muchas veces tiene su fundamento en hipótesis de responsabilidad estricta u objetiva, verbigracia el artículo 155 del Código Aeronáutico; el artículo 21 del Código de Minería; el artículo 49 de la Ley N. ${ }^{\circ} 18.302$, de 1984; el artículo $8^{\circ}$ de la Ley $N{ }^{\circ}$ 18.415, de 1985, Orgánica Constitucional de los Estados de Excepción Constitucional; el artículo 52 de la Ley N. ${ }^{\circ} 19.300$, de 1994, en materia de medio ambiente; el artículo $1^{\circ}$ de la Ley 18.617, de 1987; el artículo 144 del Decreto Ley $N .^{\circ} 222$, sobre Ley de Navegación, entre otros. En cualquier caso, para que proceda la responsabilidad civil estricta es necesario que la ley lo disponga expresamente, pues es un caso excepcional' (c. 39).

Respecto del monto "excesivo" de la indemnización (de 2 a 5 veces el importe de la factura) la sentencia precisa lo siguiente: "c) Que la aplicación de la indemnización frente a las infracciones del inciso final del articulo $4^{\circ}$ de la Ley 19.983, no importan en términos técnicos un enriquecimiento sin causa o una medida expropiatoria ni de confiscación, como lo ha explicado este Tribunal en circunstancias similares, en los considerandos séptimo y noveno a decimotercero de la sentencia Rol No 541-2006” (c. 44). Luego señala: "La dureza de la consecuencia jurídica - una indemnización que va desde el doble hasta el quintuplo del valor expresado en la factura - se entiende si se tiene a la vista que el fin que busca tutelar es proteger la cadena de pagos en el comercio. En otras palabras, la indemnización es tan alta porque no se afecta tan sólo a un agente, sino a la totalidad del mercado y, en último término, a los consumidores" (c. 55). 
El voto minoritario en contra estimaba inconstitucional la indemnización por ser desproporcionada, violentar el debido proceso y tener carácter expropiatorio. Este voto alude directamente al carácter punitivo de la misma, al señalar que el precepto permite sentencias punitivas que no se sostienen en un proceso previo, justo y racional (c. 2) y que se fuerza al juez a prodigar una indemnización que no tiene por objeto resarcir daño o perjuicio alguno causado por el deudor (c. 6).

Como podemos apreciar, en Chile se ha estimado constitucional que el legislador estatuya daños punitivos y la doctrina civil hace presente que en no pocas ocasiones las indemnizaciones por daño moral engloban consideraciones de justicia retributiva y que por ello debieran admitirse en ciertos casos indemnizaciones por daños punitivos.

\section{LA INDEMNIZACIÓN DEL ART. 489 Y SU ESPECIAL NATURALEZA LABORAL}

Con las sentencias del Tribunal Constitucional reseñadas en el párrafo anterior, puede dar la impresión que estamos de acuerdo con la tesis sostenida por una parte de los autores y alguna jurisprudencia que mencionamos en el párrafo primero de este artículo. Sin embargo, el tema es bastante más complicado.

Hemos visto cómo los daños punitivos en responsabilidad civil surgen en el common law y han sido aceptados pero con reparos en los sistemas de civil law. Los daños punitivos aluden a la necesidad de cubrir fines retributivos y de prevención general (disuasión) frente a violaciones abusivas o escandalosas para el interés público. Nuestro país no está ajeno a este tipo de consideraciones, según expusimos anteriormente.

¿Y en materia laboral? Por las razones estudiadas en el párrafo II, debemos tener presente que el derecho del trabajo construye un sistema especial de indemnizaciones de tipo tarifado, tanto para favorecer al trabajador como al empleador. Es por ello que, aunque la indemnización especial de 6 a 11 meses del art. 489 CTCh, puede parecer punitiva prima facie, sobre todo desde la óptica de la responsabilidad civil, responde desde la óptica del derecho laboral a una indemnización tarifada de daño moral.

En virtud de esta tarifa flotante, sin necesidad de que el trabajador deba probar el daño moral (lo cual podría ser tremendamente complicado) y limitando a cambio la responsabilidad del empleador ${ }^{69}$, el juez aprecia caso

${ }^{69}$ La tarifa de los daños con carácter de presunción de derecho da certeza al trabajador, dado que le exime de probar los perjuicios y también le otorga inmediatez, porque por el solo hecho del cumplimiento de la condición (el despido) se devenga el crédito en su favor. Cfr. MACHADO y OJEDA, cit. (32), p. 274. 
a caso los hechos ocurridos y según su mérito decreta la indemnización correspondiente (de 6 a 11 meses). Este mecanismo recoge en plenitud la práctica argumentativa del derecho del trabajo que hemos explicado anteriormente.

Por otro lado y precisamente en el caso de la indemnización del daño moral, cabe recordar que ésta constituye una reparación por equivalencia, atendida la naturaleza del daño, y en este sentido su naturaleza no es reparatoria si no compensatoria, porque no existe un daño patrimonial perfectamente evaluable, sino uno de intereses extrapatrimoniales no cotizables en dinero ${ }^{70}$.

Cabe considerar, además, que la utilización de tarifas o baremos no es exclusiva del derecho del trabajo. Como señala Tapia en la experiencia comparada, en materia de daños reparables, se utilizan baremos para algunas categorías de perjuicios ${ }^{71}$, permitiendo una cierta valoración objetiva de los daños por parte de los legisladores o de la práctica judicial ${ }^{72}$. Los baremos en el derecho civil permiten dar una mayor igualdad al trato entre víctimas y volver previsibles los costos de los accidentes ${ }^{73}$.

Asimismo, Barros destaca que la indemnización del daño moral está sujeta a condiciones de responsabilidad diferente que la patrimonial, pudiendo el legislador estatuir criterios razonables o baremos para limitar la indemnización. En el caso español, el Tribunal Constitucional ha fallado que el daño moral puede ser objeto de una indemnización predeterminada en base a baremos legales. En el caso de Italia, el Tribunal Constitucional ha declarado la constitucionalidad del art. 2059 del Código Civil de dicho país, que estatuye que la indemnización por daño moral sólo procede en los casos en que la ley lo disponga ${ }^{74}$.

Los baremos y topes en derecho civil y las indemnizaciones tarifadas en derecho del trabajo tienen su propia lógica, en base a las prácticas argumentativas disímiles de estas disciplinas.

La lógica laboral se preocupa del trabajador, para quien será muy difícil probar el daño moral. Sin embargo, podría ocurrir que el trabajador logre

${ }^{70}$ Fueyo Laneri, Fernando, Cumplimiento e Incumplimiento de las Obligaciones, (Santiago, Editorial Jurídica de Chile, 1992), p. 347, Barros, Enrique, cit. (1), p. 302 y TAPIA, Mauricio, cit. (63), pp. 298 y 299.

${ }_{71}$ TAPIA, Mauricio, cit. (63), p. 304.

72 TAPIA, Mauricio, cit. (63), p. 304.

73 TAPIA, Mauricio, cit. (63), p. 304. Obviamente esta técnica tiene sus limitaciones, como señala este autor, la inconmensurabilidad de los bienes de la personalidad a evaluar, la complejidad de los diversos casos de responsabilidad y cierto riesgo de arbitrariedad. Ibíd. pp. 304 y 305.

${ }^{74}$ Barros, Enrique, cit. (1), p. 253 y nota 112. 
probar excepcionalmente el daño moral sufrido. A este caso nos referiremos en el acápite siguiente.

\section{ACUMULACIÓN DE UNA INDEMNIZACIÓN DE DAÑO MORAL}

\section{CUANDO EL AFECTADO PRUEBE UN DAÑO MAYOR}

Si el trabajador lograra probar el daño moral sufrido y la necesaria compensación del mismo fuese mayor que la contemplada en la tarifa flotante del art. 489 CTCh, o sea mayor a 11 remuneraciones, no encontramos inconveniente en que sea compensado por el monto faltante.

En este sentido, no podemos menos que estar de acuerdo con la sentencia de la Corte de Apelaciones que citamos en el párrafo primero (Negrete con Belenus S.A.), en orden a que la indemnización especial del art. 489 no excluye una eventual indemnización del daño moral, si el trabajador logra probar dicho daño y el excedente. De hecho, en este caso, según se deja constancia en el considerando octavo de la sentencia de primera instancia, un informe de la Mutual de Seguridad de la Cámara Chilena de la Construcción, determinó "que la actora ha experimentado una depresión mayor, lo que declara como una enfermedad profesional, obviamente de origen laboral, acreditándose en este sentido el nexo causal entre el hostigamiento laboral y el cuadro depresivo de la demandante". Como vemos, la trabajadora logra probar un daño mayor y el juez estimó que la indemnización especial era insuficiente, en concordancia con el principio de reparación integral del daño mencionado en la misma sentencia.

No se trata de que la tarifa flotante sea punitiva, aunque desde la óptica del derecho civil pudiera ser esa su naturaleza. Estimamos que obedece a la lógica propia del derecho del trabajo, evitar que el trabajador pruebe a cambio de limitar y precisar los costos para el empleador. No obstante, si en un caso el trabajador logra probar un daño mayor, no existiría problema en completar la tarifa. En este sentido estimamos que se ha perfeccionado nuestro planteamiento original en esta materia ${ }^{75}$.

Algo parecido ocurre con los accidentes del trabajo y enfermedades profesionales, Ley $N^{\circ} 16.744$ (01/01/1968), que Establece normas sobre accidentes del trabajo y enfermedades profesionales. En efecto, su art. 69 b) dispone que las víctimas del accidente o enfermedad podrán reclamar al empleador o al tercero responsable las otras indemnizaciones a que tengan derecho, con arreglo a las prescripciones del derecho común, incluido el daño moral. Al respecto, Barros comenta que por esta vía se pueden cubrir

75 Gamonal Sergio, El procedimiento, cit. (4), p. 39 y Gamonal, Sergio, Evolución, cit. (5), p. 171. 
los daños patrimoniales y morales no compensados por el seguro ${ }^{76}$. Como las prestaciones del seguro social de accidentes y enfermedades son por daño patrimonial, si se demanda por daños patrimoniales por vía del citado art. $69 \mathrm{~b}$ ) debe tratarse de daños que no hayan sido compensados por el seguro ${ }^{77}$. En otras palabras, el demandante deberá probar un daño distinto (daño moral) o de un monto mayor al cubierto por el seguro social (daño emergente y lucro cesante). Por el contrario, el daño moral no concurre con la pretensión restitutoria del organismo asegurador ${ }^{78} \mathrm{y}$, por tanto, según el daño acreditado deberá compensarse a la víctima.

Lo anterior, ¿implica que dentro de la lógica argumentaba del derecho del trabajo no es posible recurrir a una indemnización punitiva? Obviamente la respuesta es negativa. Podría haber casos en que proceda una indemnización punitiva. El punto es que no es este el caso, donde el legislador ha contemplado expresamente una tarifa flotante de daño moral al tenor de la lógica del derecho del trabajo. Pero por ejemplo, dentro del mismo procedimiento de tutela, cuando se acciona estando aún vigente el contrato de trabajo se aplica la regla del art. $495 \mathrm{~N}^{\circ} 3$, que alude a la facultad del juez para decretar las indemnizaciones que procedan, las que según reglas generales pueden ser perfectamente por daño moral, y excepcionalmente punitivos, por ejemplo, en el caso de las prácticas antisindicales. Sin embargo, una materia como esta deberemos tratarla en otro artículo futuro.

\section{CONCluSiones}

Como hemos expuesto en este trabajo, la indemnización especial del art. 489 CTCh no tiene una naturaleza clara. Para algunos autores sería de carácter punitivo y, para otros, por daño moral.

Desde la perspectiva del derecho civil, puede entenderse como una indemnización punitiva. Sin embargo, esta indemnización especial se enmarca dentro de un procedimiento de tutela de derechos fundamentales, en el derecho del trabajo, y este derecho especializado ha desarrollado desde sus inicios un tratamiento especial en el tema indemnizatorio. Esta especialidad radica en la liberación de prueba por parte del trabajador a cambio de una limitación de responsabilidad del empleador, otorgando, asimismo seguridad a ambas partes en cuanto a los montos involucrados. Este sistema ha sido de común utilización y ha sido superado en contextos excepcionales, por ejemplo frente a un despido abusivo ${ }^{79}$.

\footnotetext{
76 Barros, Enrique, cit. (1), p. 715.

77 Barros, Enrique, cit. (1), p. 715.

${ }^{78}$ Barros, Enrique, cit. (1), p. 715.

79 Gamonal, Sergio, Evolución, cit. (5), pp. 98 y ss.
} 
Pesquisando los orígenes de las indemnizaciones tarifadas, ya se trate de una evolución de la autonomía colectiva, o de un derivado de la regla inglesa de despido, o de una legislación de carácter transaccional, nos encontramos con estos fundamentos vinculados a la certeza para ambas partes y a la liberación de prueba de la víctima a cambio de una limitación a la responsabilidad.

La indemnización del art. 489 en comento, en forma clara obedece a esta práctica argumentativa del derecho del trabajo.

Por otro lado, la naturaleza compensatoria más que reparatoria de la indemnización del daño moral, permite en ciertos casos el uso de baremos o tarifas como explicamos en este artículo.

¿Y qué ocurre si el trabajador en forma logra probar el daño moral? Lo argumentado no excluye la posibilidad de añadir una indemnización excepcional siempre que el daño acreditado sea mayor que la tarifa contemplada por la ley (de hasta 11 remuneraciones). Algo similar ocurre actualmente en los accidentes del trabajo y enfermedades profesionales cuando se demanda el daño patrimonial.

En este sentido, concordamos con la postura de algunas de las sentencias que hemos citado, pero por razones propias del derecho del trabajo, distintas de sostener la tesis de que estaríamos frente a una indemnización de daños punitivos.

\section{BiBLIOGRAFÍA}

Barros, Enrique, Tratado de Responsabilidad Extracontractual (Santiago, Editorial Jurídica de Chile, 2007).

Blackstone, William y Cooley, Thomas M., Commentaries of the Laws of England, Libro1 vol. 1, (tercera edición revisada -la primera es de 1765- incluyendo los comentarios, referencias y notas de Thomas M. Cooley. Chicago, Callaghan and Company, 1884).

CaAmaño, Eduardo, El Derecho a la No Discriminación en el Empleo (Santiago, LexisNexis, 2005).

Camerlynck, G.H. y Lyon-Caen, G., Derecho del Trabajo (primera edición en francés de 1963, traducción de Juan M. Ramírez, Madrid, Aguilar, 1974).

Cooter, Robert D., Punitive Damages, Social Norms, and Economic Analysis, en Law and Contemporary Problems, 60 (1997) 3, pp. 73-91.

Couturier, Gérard, Droit du Travail (tercera edición, París, PUF, 1996).

Deveali, Mario, Lineamientos de Derecho del Trabajo (Buenos Aires, Tipográfica Editores Argentina, 1948).

Fueyo LANERI, Fernando, Cumplimiento e Incumplimiento de las Obligaciones (Santiago, Editorial Jurídica de Chile, 1992).

Galiana Moreno, Jesús M., El Contrato de Trabajo en el Derecho Inglés (Barcelona, Bosch, 1978). 
Gamonal C., Sergio y Rosado Marzán, César, El Principio de Protección del Trabajador en el Derecho Norteamericano (Santiago, Thomson Reuters, 2014).

Gamonal Contreras, Sergio, El Daño Moral por Término del Contrato de Trabajo, en Revista de Derecho Laboraly Seguridad Social, I Thomson Reuters Chile (2013) 1, pp. 124-128.

Gamonal C., Sergio, Evolución del Daño Moral por Término del Contrato de Trabajo en el Derecho Chileno, en Revista de Derecho, Pontificia Universidad Católica de Valparaíso XXXIX (2012) 2 semestre, pp. 161-176.

Gamonal C., Sergio, El procedimiento de tutela de derechos laborales (2a edición, Santiago, LexisNexis, 2008).

Gamonal C., Sergio, El Daño Moral en el Contrato de Trabajo (2a edición, Santiago, LexisNexis, 2007).

Gamonal C., Sergio y Prado López, Pamela, El Mobbing o Acoso Moral Laboral (Santiago, LexisNexis, 2006).

Gamonal C., Sergio, Ciudadanía en la Empresa o los derechos fundamentales inespecificos (Montevideo, Fundación de Cultura Universitaria, 2004).

Gamonal Contreras, Sergio, El Daño Moral por Término del Contrato de Trabajo (Santiago, Editrem, 2000).

García Matamoros, Laura Victoria y Herrera Lozano, María Carolina, El concepto de los daños punitivos o punitive damages, en Estudios Socio-Jurídicos, Bogotá 5 (2003) (1), pp. 211-229.

Gordon, Robert W., Corporate Law Practice as a Public Calling, en Maryland Law Review, 49 (1990) 2, p. 255-292.

Kemp, David S. (2013), The Constitution and Punitive Damages: A Ten years Anniversary Discussion of State Farm v. Campbell, en Verdict, Legal Analysis and Commentary from Justia, (2013) (visible en internet: https://verdict.justia.com/2013/04/08/ the-constitution-and-punitive-damages).

KuInck, Robert A., Symposium: Reforming Punitive Damages. The Punitive Damage Debate, en Harvard Journal on Legislation, 38 (2001), pp. 469-485.

Langé, Daniel, Droit du Travail (París, Ellipses, 2003).

Machado, José Daniel y OJedA, Raúl Horacio, Las Indemnizaciones Debidas como Consecuencia de la Extinción de la Relación de Trabajo, en Ackerman, Mario E. (edit.) y Tosca, Diego M. (coord.), Tratado de Derecho del Trabajo, Tomo IV, (Buenos Aires, Rubinzal-Culzoni Editores, 2005), pp. 233-471.

Mallor, Jane P., Punitive Damages for Wrongful Discharge of At Will Employees, en William and Mary Law Review, 26 (1985), pp. 449-496.

Martorell, Ernesto E., Indemnización del daño moral por despido ( $2^{\mathrm{a}}$ edición, Buenos Aires, Hammurabi, 1994).

Melis, Christian, Los Derechos Fundamentales de los Trabajadores como Limites a los Poderes Empresariales (Santiago, LegalPublishing, 2009).

Morriss, Andrew P., The Story of the Montana Wrongful Discharge from Employment Act: A Drama in 5 Acts, en Estreicher, Samuel y Lester, Gillian (editores), Employment Law Stories (Nueva York, Thomson West, 2007), pp. 237-276.

Pereira Fredes, Esteban, Un Alegato a Favor de las Consideraciones Punitivas en el Derecho Privado, en Revista de Derecho, Escuela de Posgrado U. de Chile, 7 (2015), pp. 61-78.

PiCcinini, Iolanda, Equitá e diritto del lavoro (Padua, CEDAM, 1997).

Pizarro, Ramón Daniel, Daño moral (Buenos Aires, Hammurabi, 1996). 
PRIEST, George L., La reforma del régimen de daños punitivos: el caso de Alabama, en Rosenkrantz, Carlos F. (comp.), La Responsabilidad Extracontractual (traducción de Carlos F. Rosenkrantz, Barcelona, Gedisa, 2005), pp. 301-311.

Priest, George L., Punitive Damages and Enterprise Liability, en Southern California Law Review, 56 (1982), pp. 123-132.

Rivero, Jean y Savatier, Jean, Droit du Travail (décimo tercera edición, París, PUF, 1993).

Rojas Miño, Irene, La naturaleza Jurídica de la Indemnización por Término de Contrato de Trabajo en el Ordenamiento Laboral Chileno, en Revista de Derecho, Pontificia Universidad Católica de Valparaíso XLI (2013) 2 semestre, pp. 107-143.

Ruprecht, Alfredo, Contrato de Trabajo, en Enciclopedia Jurídica OMEBA, Tomo IV (Buenos Aires, Driskill, 1979), pp. 397-485.

Salvador Coderch, Pablo, Punitive Damages, en InDret Revista para el Análisis del Derecho (2000) 01, pp. 1-17, (visible en internet: www.indret.com).

Süsseskind, Arnaldo, Maranhäo, Délio, Vianna, Segadas, y TeXeIra, Lima, Instituçiôes de Direito do Trabalho, Tomo I (Sao Paulo, LTr, 1997), I.

Tapia Rodríguez, Mauricio, Código Civil 1855-2005, Evolución y Perspectivas (Santiago, Editorial Jurídica de Chile, 2005).

Ugarte, José Luis, Tutela de Derechos Fundamentales del Trabajador (Santiago, LegalPublishing, 2009).

Ugarte, José Luis, El Nuevo Derecho del Trabajo (Santiago, Editorial Universitaria, 2004).

VÁzQuez Vialard, Antonio, La responsabilidad en el derecho del trabajo (Buenos Aires, Astrea, 1988).

Walker Errázuriz, Francisco y Arellano Ortiz, Pablo, Derecho de las Relaciones Laborales. Un derecho vivo (Santiago, Librotecnia, 2014).

Normas citadas

Código del Trabajo

Código Civil

Código Civil italiano

Ley $\mathrm{N}^{\circ} 16.744(01 / 01 / 1968)$, que establece normas sobre accidentes del trabajo y enfermedades profesionales

Ley $\mathrm{N}^{\circ} 19.628(28 / 08 / 1999)$ sobre protección de la vida privada

Ley $\mathrm{N}^{\circ} 19.983(15 / 12 / 2004)$, que regula la transferencia y otorga mérito ejecutivo a la factura

Ley No 20.323 (20/01/2009), que Mmodifica la Ley 19.983 con el objeto de facilitar la factorización de facturas por pequeños y medianos empresarios

DFL N 164 , de 1991, Ley de Concesiones (cuyo texto fue refundido, coordinado y sistematizado por el Decreto 900 de Obras Públicas, del 18/12/1996)

Jurisprudencia citada

Tribunal Constitucional, Rol N 541-2006 (26/12/2006) (requerimiento de inconstitucionalidad)

Tribunal Constitucional,Rol No 1564-2009 (07/12/2010) (requerimiento de inconstitucionalidad) 
Corte Suprema, Jara con I. Municipalidad de La Ligua. (2014): (unificación de jurisprudencia) Corte Suprema, cuarta sala laboral, 7 de octubre de 2014, Rol 2746-2014

Corte Suprema, López Baleisán Rosa con Municipalidad de Los Andes. (2012): (recurso de casación en el fondo) Corte Suprema, tercera sala constitucional, 23 de octubre de 2012, Rol No 8871-09

Corte Suprema, Suazo con Codelco Chile. (2011): (recurso de casación en la forma) Corte Suprema, primera sala civil, 4 de abril de 2011, Rol N 7270-2009

Corte de Apelaciones, Negrete con Belenus S.A. (2013): (recurso de nulidad) Décima Sala Corte de Apelaciones de Santiago, 8 de mayo de 2013, Nº 338-2013

Primer Juzgado de Letras del Trabajo de Santiago, Negrete con Belenus S.A. (2013): (acción de tutela laboral) 4 de febrero de 2013, RIT T-559-2012.

Primer Juzgado de Letras del Trabajo de Santiago, Omerovich con ISS Servicios Generales (2011): (acción de tutela laboral) 23 de mayo de 2011, RIT Nº T-63-2011

Segundo Juzgado de Letras del Trabajo de Santiago, Miranda con Redbus Urbano. (2009): (acción de tutela laboral) 16 de noviembre de 2009, RIT N ${ }^{\circ}$ T-4-2009

Corte Suprema federal de Estados Unidos: Day v. Woodworth, 54 U.S. 363 (1851)

Corte Suprema federal de Estados Unidos (Corte Suprema federal): State Farm Mutual Insurance Co. v. Campbell 538 U.S. 408 (2003)

Corte Suprema de Montana: Flanigan v. Prudential Federal Savings, 720 P.2d 257 (Mont. 1986)

Gran Bretaña: Beeston v. Collyer (1827) 4 Bing 307

Gran Bretaña: Baxter v. Nurse (1844) 6 Man. \& G 936

Gran Bretaña: Fairman v. Oaford (1860) 5 H. \& N. 635 
